\title{
The Association of Autism Spectrum Disorders and Symptoms of Asthma, Allergic Rhinoconjunctivitis and Eczema among Japanese Children Aged 3 - 6 Years
}

\author{
Daisuke Hori' ${ }^{1}$, Hiromasa Tsujiguchi' ${ }^{1}$, Yasuhiro Kambayashi' ${ }^{1}$, Toshio Hamagishi', \\ Masami Kitaoka', Junko Mitoma', Hiroki Asakura', Fumihiko Suzuki', Enoch Olando Anyenda', \\ Nguyen Thi Thu Thao', Yohei Yamada1, Satoko Tamai', Koichiro Hayashi', Yuri Hibino1, \\ Aki Shibata1, Takiko Sagara1, Shinichiro Sasahara², Ichiyo Matsuzaki2,3, Hiroyuki Nakamura1 ${ }^{*}$ \\ ${ }^{1}$ Department of Environmental and Preventive Medicine, Graduate School of Medical Science, Kanazawa University, Kanazawa, \\ Japan \\ ${ }^{2}$ Faculty of Medicine, University of Tsukuba, Tsukuba, Japan \\ ${ }^{3}$ International Institute for Integrative Sleep Medicine, University of Tsukuba, Tsukuba, Japan \\ Email: *hori_d@mbr.nifty.com, *hiro-n@po.incl.ne.jp
}

How to cite this paper: Hori, D., Tsujiguchi, H., Kambayashi, Y., Hamagishi, T., Kitaoka, M., Mitoma, J., Asakura, H., Suzuki, F., Anyenda, E.O., Thao, N.T.T., Yamada, Y., Tamai, S., Hayashi, K., Hibino, Y., Shibata, A., Sagara, T., Sasahara, S., Matsuzaki, I. and Nakamura, H. (2017) The Association of Autism Spectrum Disorders and Symptoms of Asthma, Allergic Rhinoconjunctivitis and Eczema among Japanese Children Aged 3 - 6 Years. Health, 9, 1235-1250.

https://doi.org/10.4236/health.2017.98089

Received: June 23, 2017

Accepted: August 22, 2017

Published: August 25, 2017

Copyright () 2017 by authors and Scientific Research Publishing Inc. This work is licensed under the Creative Commons Attribution International License (CC BY 4.0).

http://creativecommons.org/licenses/by/4.0/

(c) (i) Open Access

\begin{abstract}
There is insufficient epidemiological evidence on the relationship between autism spectrum disorder (ASD) and allergic diseases. We performed a cross-sectional survey to elucidate the associations between them using validated screening tools. The participants were children aged $3-6$ years attending kindergarten or nursery school in Shika Town, Japan ( $\mathrm{n}=417$; valid response rate $=80.4 \%)$. Autism spectrum features were scored on the Social Communication Questionnaire (SCQ). Allergic symptoms (asthma, allergic rhinoconjunctivitis, and eczema) were determined according to the criteria of the International Study of Asthma and Allergies in Childhood. A total of 15 children (4.5\%) had an SCQ score of 11 points or higher. The prevalence of symptoms was $14.7 \%$ for asthma, and $5.3 \%$ for allergic rhinoconjunctivitis, and $11.4 \%$ for eczema. Logistic regression indicated that symptoms of eczema were significantly associated with SCQ scores of 11 points or higher [odds ratio (OR), 4.38; 95\% confidence interval (CI), 1.41 - 13.59]. The association persisted after adjustment for age, sex, and BMI (OR, 3.84; 95\% CI, 1.20 12.24). Moreover, asthmatic symptoms were significantly associated with male sex (OR, 2.09; 95\% CI, 1.12 - 3.92) and overweight status (OR, 2.45; 95\% CI, 1.03 - 5.83). This suggests that higher SCQ scores, which imply more autism spectrum features, are associated with higher prevalence of eczema symptoms. While no causal relationships can be made, ASD might be associated with
\end{abstract}


eczema.

\section{Keywords}

Asthma, Autism Spectrum Disorder, Eczema, Early Screening, Social Communication Questionnaire

\section{Introduction}

Autism spectrum disorder (ASD) is a group of developmental disorders characterized by both persistent deficits in social communication and social interaction across multiple contexts and restricted, repetitive patterns of behavior, interests, or activities [1]. The aforementioned symptoms must also be present in the early developmental period. On the other hand, allergies are hypersensitivity disorders of the immune system in which both innate and acquired immunities may contribute to the development of allergic diseases (i.e., asthma, allergic rhinoconjunctivitis and eczema) [2] [3]. Although the cause of ASD remains unknown in many cases [4], recent observational studies have demonstrated that allergic diseases were more frequently seen in children with ASD compared to typically developing children, suggesting involvement of environmental factors in the development of both diseases [5]-[10]. For example, our previous study [11] found a significant association between nasal allergy and high autism score using the Autism Screening Questionnaire (ASQ) among Japanese children aged 3 - 5 years old [12]. An analysis of the National Health Insurance Database in Taiwan by Chen et al. revealed that atopic diathesis in early childhood elevated the future risk of developing ASD [13]. A meta-analysis by Miyazaki et al. reported that there was a significantly higher estimated prevalence of asthma and allergic rhinoconjunctivitis in children with ASD compared to typically developing children [14]. However, in an American study, Jyonouchi et al. reported that an ASD group was not associated with atopic/non-atopic asthma, allergic rhinitis, and atopic dermatitis [5]. The controversial reports in the literature and limited epidemiological evidence therefore render the association between allergic disease and ASD unclear.

Although the prevalence of ASD remains unknown in Japan due to the lack of large epidemiological studies, the prevalence of ASD is estimated to be on the increase all over the world [15]. It is estimated that the prevalence of ASD is about $1.5 \%$ of children in the U.S. [16], and $2 \%$ of children in the general population in Korea [17]. The prevalence of allergic diseases has also increased rapidly over the last few decades in developing countries, including Japan [18] [19]. Therefore, the concomitant increases of both ASD and allergic diseases represent a potentially important and unique public health burden.

Until now, prevalence and risk factors for allergic diseases have been studied extensively in school age children but there is little information about younger children. Moreover, few epidemiological studies have examined the association 
between allergic diseases and ASD, especially among younger children. Another limitation of the recent epidemiological studies on allergic diseases in ASD children is that they investigated diagnosed ASD only which is not necessarily ideal in epidemiological surveys for young children. It is estimated that ASD affects approximately $2 \%$ of children in the general population and more than half of the cases are undiagnosed and untreated [17]. Moreover, in a Japanese nationwide survey of adults with high-functioning ASD, they were first diagnosed at an average age of 10 years [20]. Thus, there is a high probability of missing possible ASD cases if employing only the diagnosed cases in surveying early childhood morbidity. In addition, comprehensive diagnostic assessment is often expensive and time-consuming work completed by a multidisciplinary team of professionals [21], and this can be stressful for children being assessed as well as their parents. Screening method improvements could thusly decrease the specific problem of diagnostic bias due to gaps in socioeconomic status or access to medical services [22] [23].

In this paper, we describe the prevalence of symptoms of asthma, allergic rhinoconjunctivitis and eczema and clarify the association between allergic symptoms and autism spectrum features. Data were gathered with an epidemiological approach using validated screening tools in rural, Japanese, preschool-aged children (3 - 6 years). To assess autism spectrum features in these children, we used the Social Communication Questionnaire (SCQ) [24], formerly known as ASQ. For allergic diseases, we used a standardized questionnaire of the International Study of Asthma and Allergies in Childhood (ISAAC) [18] [19] [25] [26]. We hypothesized that the prevalence of allergic symptoms would be higher in children with autistic spectrum features than those without. We also investigated potential risk factors associated with allergic symptoms and ASD, including sex, age, and body mass index (BMI). These results could serve as guidelines for prevention and treatment of allergic diseases in children with ASD.

\section{Materials and Methods}

\subsection{Subjects and Sampling}

Our cross-sectional questionnaire-based survey was conducted in Shika Town, Ishikawa prefecture, Japan. Shika is a rural town located in the Noto peninsula with a total population of almost 22,500. The Shika study is an ongoing population-based survey which aims to investigate the lifestyle and health status of the Japanese population [27] [28]. This survey was conducted from October to November, 2013. The self-administered questionnaires and envelops were distributed for each child at all 7 preschools (1 kindergarten and 6 nursery schools) in the towns, with the parents then taking it home to be filled out. Prior to filling out the questionnaire, all participants in the study provided informed consent. The children's parents completed the questionnaire. The number of children $(\mathrm{n}=417)$ accounted for $99.0 \%$ of the total population of 3- to 6-year-old children in the town $(\mathrm{n}=421)$ in 2013. The questionnaire was written in Japanese 
and comprised questions about sex, age, height, weight, symptoms on allergic diseases and the SCQ. After completing the form, the questionnaires were taken back to the kindergartens and nursery schools for collection and returned to our university. In the returned 406 questionnaires, there is no missing data on variables age, sex, height and weight. Regarding the SCQ, forms with more than four items missing were excluded from the statistical analysis $(n=61)$. Moreover, forms with missing data on allergic symptoms were excluded $(n=4)$, leaving a total sample of 341 and a valid response rate of $81.8 \%$. Of the 341 children analyzed, $46.6 \%$ were male $(n=159)$. Their age distribution was $11.7 \%$ for 3 -year-old $(\mathrm{n}=40), 33.4 \%$ for 4 -year-old $(\mathrm{n}=114), 36.1 \%$ for 5 -year-old $(\mathrm{n}=$ $123)$, and $18.8 \%$ for 6 -year-old $(n=64)$. A median age \pm SD was $4.6 \pm 0.9$ years old. A mean \pm SD height was $106.4 \pm 7.4 \mathrm{~cm}$, and a mean \pm SD weight was 17.7 $\pm 3.3 \mathrm{~kg}$.

\subsection{Screening Tool for ASD}

The SCQ lifetime Japanese version was used [24] [29]. It is a parent-report questionnaire designed to screen children who may need a more comprehensive evaluation because of possible ASD. It is composed of 38 items that assess specific ASD-related behaviors, such as communication with other children and nonverbal contact. It is based on the Autism Diagnostic Interview-Revised (ADI-R) algorithm [30], which is accepted as a standardized interview-based diagnostic instrument. The SCQ assesses the three core areas of functioning characteristic of youth with ASD; reciprocal social interaction, language and communication, and repetitive and stereotyped patterns of behavior. The SCQ is one of the most widely used and studied screening instruments for identifying individuals at risk for ASD [31] [32] [33] [34] [35]. In the Japanese version, a question on pronoun reversal is omitted because Japanese verbal language seldom uses a pronoun (i.e. "you" or "s/he"). Each item was rated on a two-point scale ( $0=$ "no" and $1=$ "yes") and the range of possible scores is 0 to 38 , with higher scores indicating more autistic symptomatology. Several clinical cutoff scores of the SCQ have been suggested so far (e.g. 11, 12, 15 or higher), and researchers appear to agree optimal cut-off score is dependent upon the context and nature of the study population. Among young children, a lower cut-off score is recommended [31] [32] [36]. Thus, we categorized children into 2 groups: children with SCQ scores $\geq 11$ as possible ASD cases and children with SCQ scores $<11$ as non-ASD cases.

\subsection{Measurement of Allergic Symptoms}

We used the Japanese version of the ISAAC written questionnaire for 6 - 7 year olds [37]. ISAAC is an international epidemiological research program established in 1991 and formally closed in 2012. The questionnaire was originally developed to assess the worldwide prevalence of asthma, allergic rhinoconjunctivitis and eczema among children aged 6 - 7 years in the general population and to 
search possible risk factors that could affect allergic diseases. However, it is now used for younger children in multiple studies [38] [39] [40] [41] [42].

Symptoms of asthma were estimated by positive answers to the following two questions: "Has your child ever had wheezing or whistling in the chest at any time in the past?" and "Has your child had wheezing or whistling in the chest in the past 12 months?" Affirmative answers to the following three questions were required to confirm the presence of symptoms of allergic rhinoconjunctivitis: "Has your child ever had a problem with sneezing, or a runny, or blocked nose when he/she did not have a cold or the flu?", "In the last 12 months, has your child had a problem with sneezing, or a runny, or blocked nose when he/she did not have a cold or the flu?" and "In the past 12 months, has this nose problem been accompanied by itchy/watery eyes?". Symptoms of eczema were defined as present in the case of positive responses to all the following three questions: "Has your child ever had an itchy rash which was coming and going for at least six months?", "Has your child had this rash at any time in the past 12 months?" and "Has this itchy rash at any time affected any of the following places: the folds of the elbows, behind the knees, in front of the ankles, under the buttocks, or around the neck, ears, or eyes?".

\subsection{Weight Abnormalities}

BMI was calculated as body weight in kilograms divided by height squared in meters. International age- and sex-specific cutoff points for BMI as defined by the International Obesity Task Force (IOTF) were used to define underweight, normal weight, and overweight [43] [44] [45]. These cutoff points are linked to the widely accepted adult BMI cutoff points of 18.5 for underweight, and 25 for overweight. Obesity was not defined in this study because of the small proportion of obesity in Japanese children (i.e., $2.38 \%$ of boys and $2.49 \%$ of girls in 2013) [46].

\subsection{Statistical Analysis}

We evaluated differences between variables of interest within each of the three allergy symptoms, using chi-square or Fisher's exact testing for categorical variables (SCQ dichotomized by cutoff score, sex and categories of BMI), t-tests for continuous variables with normal distribution (age), and Mann-Whitney U tests for continuous variables with non-normal distribution (total SCQ score). We performed univariate logistic regression analyses to calculate the unadjusted odds ratios (OR) and the $95 \%$ confidence intervals (CI) and reported the crude association of variables with likelihood of each allergic symptom (positive $=1$, negative $=0$ ). Furthermore, we performed forced entry methods of three separated multivariate logistic regression analyses. All statistical tests were two-tailed. $\mathrm{P}$ values less than 0.05 were regarded as indicating statistical significance. IBM SPSS for Windows, Version 22.0 (IBM Corp., Armonk, NY, USA) was used for all statistical analyses. 


\subsection{Ethical Approval}

We obtained informed consent for study participation from the parents. All procedures performed in studies involving human participants were in accordance with the ethical standards of both institutional and national research committees and with the 1964 Helsinki declaration and its later amendments or comparable ethical standards. Ethical approval to conduct the present study was received from the Kanazawa University Medical Research Ethics Committee (reference number: 1464).

\section{Results}

Figure 1 demonstrates the range and distribution of the total SCQ scores of the 341 children. The data had a range of $0-20$, with a mean (standard error: SE) of 3.66 (0.19). The distribution was not normal, and was skewed to the right (skewness $=1.67$, kurtosis $=3.48)$. In the present sample, 15 children $(4.5 \%)$ had SCQ scores $\geq 11$.

Table 1 summarizes the characteristics of children, classified by each allergic symptom. A total of 50 (14.7\%) children reported a symptom of asthma, 18 (5.3\%) reported a symptom of allergic rhinoconjunctivitis, and 39 (11.4\%) reported a symptom of eczema. Compared to girls, boys were significantly more likely to have a symptom of asthma $(\mathrm{p}=0.018)$. The prevalence of a symptom of eczema was $33.3 \%$ for children with SCQ score $\geq 11 \%$ and $10.4 \%$ for children with SCQ score $<11$ with this difference showing statistical significance $(\mathrm{p}=$ $0.019)$. We performed post hoc test and revealed the statistical power (1- $\beta$ ) was 0.63 . There were no statistically significant differences within total SCQ score age and BMI categories between two groups divided by allergic symptoms.

ORs and 95\% CIs for symptom of asthma, rhinoconjunctivitis and eczema

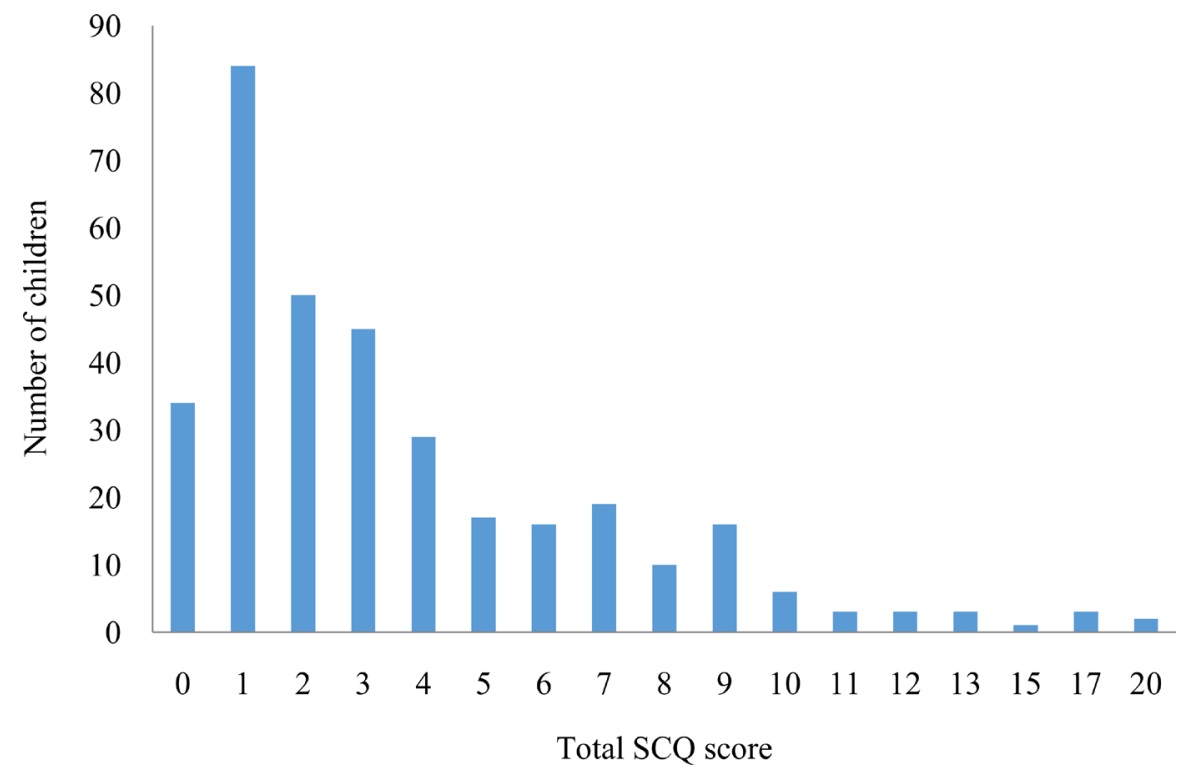

Figure 1. The range and distribution of total SCQ scores among children aged 3 - 6 years in Shika Town $(\mathrm{n}=341)$. 
Table 1. Characteristics of the children stratified by positive symptoms of asthma, rhinoconjunctivitis, and eczema $(\mathrm{n}=341)$.

\begin{tabular}{|c|c|c|c|c|c|c|c|c|c|c|}
\hline & \multicolumn{3}{|c|}{ Asthma symptom } & \multicolumn{4}{|c|}{ Allergic rhinoconjunctivitis symptom } & \multicolumn{3}{|c|}{ Eczema symptom } \\
\hline & Positive & Negative & $p$ value & & sitive & Negative & $p$ value & Positive & Negative & $p$ value \\
\hline & $50(14.7 \%)$ & $291(85.3 \%)$ & & & $(5.3 \%)$ & $323(94.7 \%)$ & & $39(11.4 \%)$ & $302(88.6 \%)$ & \\
\hline \multicolumn{11}{|c|}{ SCQ score, mean (SE) } \\
\hline Continuous & $4.03(0.52)$ & $3.61(0.21)$ & $0.412^{\mathrm{a}}$ & & $9(1.02)$ & $3.60(0.19)^{\mathrm{a}}$ & $0.161^{\mathrm{a}}$ & $4.71(0.84)$ & $3.54(0.19)$ & $0.671^{\mathrm{a}}$ \\
\hline \multicolumn{11}{|l|}{ SCQ score, n (\%) } \\
\hline 11 or higher & $3(20.0 \%)$ & $12(80.0 \%)$ & $0.469^{\mathrm{b}}$ & & $15.4 \%)$ & $13(84.6 \%)$ & $0.184^{\mathrm{b}}$ & $5(33.3 \%)$ & $10(66.7 \%)$ & $0.019^{\mathrm{b}}$ \\
\hline Under 11 & $47(14.4 \%)$ & $279(85.6 \%)$ & & & $(4.9 \%)$ & $310(95.1 \%)$ & & $34(10.4 \%)$ & $292(89.6 \%)$ & \\
\hline \multicolumn{11}{|l|}{ Age, mean $\pm S D$} \\
\hline Continuous & $4.70 \pm 0.91$ & $4.60 \pm 0.92$ & $0.500^{c}$ & & $5 \pm 0.71$ & $4.62 \pm 0.93$ & $0.765^{c}$ & $4.41 \pm 0.88$ & $4.65 \pm 0.92$ & $0.133^{c}$ \\
\hline \multicolumn{11}{|l|}{ Gender, n (\%) } \\
\hline Boy & $31(19.5 \%)$ & $128(80.5 \%)$ & $0.018^{\mathrm{d}}$ & & $(6.3 \%)$ & $149(93.7 \%)$ & $0.435^{\mathrm{d}}$ & 19 (11.9\%) & $140(88.1 \%)$ & $0.781^{\mathrm{d}}$ \\
\hline Girl & $19(10.4 \%)$ & $163(89.6 \%)$ & & & $(4.4 \%)$ & $174(95.6 \%)$ & & $20(11.0 \%)$ & $162(89.0 \%)$ & \\
\hline \multicolumn{11}{|l|}{ BMI, n (\%) } \\
\hline Underweight & $8(14.5 \%)$ & 47 (85.5\%) & $0.144^{\mathrm{d}}$ & 2 & $(3.6 \%)$ & $53(96.4 \%)$ & $0.779^{\mathrm{b}}$ & $9(21.1 \%)$ & $46(15.1 \%)$ & $0.448^{\mathrm{d}}$ \\
\hline Normal weight & $33(13.1 \%)$ & $218(86.9 \%)$ & & 15 & $(6.0 \%)$ & $236(94.0 \%)$ & & $26(68.4 \%)$ & $225(74.9 \%)$ & \\
\hline Overweight & $9(25.7 \%)$ & $26(74.3 \%)$ & & 1 & $(2.9 \%)$ & 34 (97.1\%) & & $4(11.4 \%)$ & $31(88.6 \%)$ & \\
\hline
\end{tabular}

SCQ: Social Communication Questionnaire; SE: standard error; SD: standard deviation; BMI: body mass index. a. Mann-Whitney U test; b. Fisher's exact test; c. T test; $d$. Chi square test.

Table 2. Results of logistic regressions on positive symptoms of asthma by SCQ score and other variables.

\begin{tabular}{ccccccc}
\hline & \multicolumn{5}{c}{ Asthma symptom } \\
\cline { 2 - 7 } & \multicolumn{5}{c}{ Unadjusted } & \multicolumn{3}{c}{ Adjusted } \\
\cline { 2 - 7 } & OR & $95 \%$ CI & $p$ value & OR & $95 \%$ CI & $p$ value \\
\hline SCQ score (vs Under 11) & & & & & & \\
11 or higher & 1.46 & $(0.40-5.38)$ & 0.567 & 1.26 & $(0.32-4.87)$ & 0.741 \\
Age & & & & & & \\
Continuous & 1.12 & $(0.81-1.56)$ & 0.490 & 1.07 & $(0.76-1.49)$ & 0.709 \\
Gender (vs Girl) & & & & & & \\
Boy & 2.06 & $(1.11-3.81)$ & 0.022 & 2.09 & $(1.12-3.92)$ & 0.021 \\
BMI (vs Normal Weight) & & & & & & \\
Underweight & 1.17 & $(0.51-2.70)$ & 0.714 & 1.11 & $(0.48-2.60)$ & 0.808 \\
Overweight & 2.37 & $(1.02-5.51)$ & 0.046 & 2.45 & $(1.03-5.83)$ & 0.043 \\
\hline
\end{tabular}

OR: odds ratio; CI: confidence interval: SCQ: Social Communication Questionnaire; BMI: Body mass index.

corresponding to other variables are shown in Tables $2-4$, respectively. In the crude model, children with an SCQ score of 11 points or higher were more likely to have eczema compared to other children $(\mathrm{OR}=4.38$; $95 \% \mathrm{CI}=1.41-13.59$; 
Table 3. Results of logistic regressions on positive symptoms of rhinoconjunctivitis by SCQ score and other variables.

\begin{tabular}{ccccccc}
\hline & \multicolumn{5}{c}{ Rhinoconjunctivitis symptom } \\
\cline { 2 - 6 } & \multicolumn{5}{c}{ Unadjusted } & \multicolumn{3}{c}{ Adjusted } \\
\cline { 2 - 7 } & OR & $95 \%$ CI & $p$ value & OR & $95 \%$ CI & $p$ value \\
\hline SCQ score (vs Under 11) & & & & & & \\
11 or higher & 2.94 & $(0.61-14.16)$ & 0.178 & 3.32 & $(0.66-16.72)$ & 0.146 \\
Age & & & & & & \\
Continuous & 0.93 & $(0.55-1.55)$ & 0.770 & 0.94 & $(0.56-1.58)$ & 0.805 \\
Gender (vs Girl) & & & & & & \\
Boy & 1.44 & $(0.56-3.76)$ & 0.451 & 1.47 & $(0.56-3.85)$ & 0.439 \\
BMI (vs Normal Weight) & & & & & & \\
Underweight & 0.61 & $(0.14-2.77)$ & 0.526 & 0.54 & $(0.12-2.49)$ & 0.427 \\
Overweight & 0.48 & $(0.06-3.71)$ & 0.478 & 0.43 & $(0.05-3.45)$ & 0.425 \\
\hline
\end{tabular}

OR: odds ratio; CI: confidence interval: SCQ: Social Communication Questionnaire; BMI: body mass index.

Table 4. Results of logistic regressions on positive symptoms of eczema by SCQ score and other variables.

\begin{tabular}{ccccccc}
\hline & \multicolumn{5}{c}{ Eczema Symptom } \\
\cline { 2 - 6 } & \multicolumn{5}{c}{ Unadjusted } & \multicolumn{3}{c}{ Adjusted } \\
\cline { 2 - 7 } & OR & $95 \%$ CI & $p$ value & OR & $95 \%$ CI & $p$ value \\
\hline SCQ score (vs Under 11) & & & & & & \\
11 or higher & 4.38 & $(1.41-13.59)$ & 0.011 & 3.84 & $(1.20-12.24)$ & 0.023 \\
Age & & & & & & \\
Continuous & 0.74 & $(0.51-1.08)$ & 0.115 & 0.77 & $(0.53-1.12)$ & 0.171 \\
Gender (vs Girl) & & & & & & \\
Boy & 1.15 & $(0.59-2.26)$ & 0.683 & 1.17 & $(0.59-2.34)$ & 0.655 \\
BMI (vs Normal Weight) & & & & & & \\
Underweight & 1.53 & $(0.65-3.60)$ & 0.328 & 1.35 & $(0.56-3.25)$ & 0.504 \\
Overweight & 1.15 & $(0.38-3.52)$ & 0.808 & 1.06 & $(0.34-3.38)$ & 0.916 \\
\hline
\end{tabular}

OR: odds ratio; CI: confidence interval: SCQ: Social Communication Questionnaire; BMI: body mass index.

$\mathrm{p}=0.011)($ Table 4). When the model was adjusted for age, sex and BMI categories, the association remained statistically significant $(\mathrm{OR}=3.84 ; 95 \% \mathrm{CI}=1.20$ 12.24; $\mathrm{p}=0.023)$. In the adjusted model, being male $(\mathrm{OR}=2.09 ; 95 \% \mathrm{CI}=1.12$ 3.92; $\mathrm{p}=0.021)$ and overweight $(\mathrm{OR}=2.45 ; 95 \% \mathrm{CI}=1.03-5.83 ; \mathrm{p}=0.043)$ were shown to be statistically significantly related to asthma (Table 2). Overall, allergic rhinoconjunctivitis was not associated with SCQ classification, age, sex, and weight abnormalities.

\section{Discussion}

In 2013, we examined the prevalence of asthma, allergic rhinoconjunctivitis and 
eczema among children in kindergarten and nursery schools in Shika Town, Japan. Furthermore, we found that preschool-aged children with autism spectrum features had an increased likelihood of suffering from symptom of eczema. A statistically significant association persisted after adjusting for age, sex, and BMI categories. To our knowledge, this is the first study using validated screening measures that shows a higher prevalence of eczema symptoms in children aged 3 6 years with autism spectrum features compared to those without. This seminal result may be due to the effective simplicity of screening tools such as the ISAAC questionnaire and SCQ. While the cross-sectional nature of the study makes a causal conclusion impossible, the theory that autism spectrum traits would be related to eczema is supported. In contrast, we did not confirm any results from recent studies which suggest that asthma or allergic rhinoconjunctivitis are associated with ASD.

Among the participants analyzed, $4.4 \%(\mathrm{n}=15)$ were presumed to have ASD suggesting that some cases with SCQ scores $\geq 11$ were false positives. We recognized that the SCQ could not be a replacement for a clinician-verified diagnosis and we acknowledge, as illustrated in Figure 1, that it is difficult to clearly distinguish possible ASD cases from others by screening tools. However, Sivertsen et al. employed the Autism Spectrum Screening Questionnaire in their study and argued that a strict categorical diagnosis would not be useful in epidemiological studies because ASD is a spectrum problem [47]. Johnson et al. pointed out that children with false positive screens are a high risk group for other neuro-cognitive and behavioral impairments and further assessment would be beneficial [48]. Thus, we considered that the prevalence subsumed borderline ASD cases, not implying a marked overestimate. The identification of undiagnosed and untreated ASD is important, with the potential to help parents increase knowledge of ASD and improve interaction with their children from earlier ages [49].

Epidemiological study of allergic symptoms using the ISAAC questionnaire among Japanese preschool age children is scarce in the literature. We compared the present results from Shika Town (asthma, allergic rhinoconjunctivitis, eczema; $14.7 \%, 5.3 \%, 11.4 \%)$ with those obtained using the same questionnaire in the Ogasawara Islands, and Setagaya, Japan. The prevalence of asthma symptoms found in this study was higher than the study of preschool children conducted in the Ogasawara Islands (asthma, 12.2\%) [50]. The prevalence of three allergic disease symptoms found in this study was lower than in the study of 6-year-old school children conducted in Setagaya (asthma, allergic rhinoconjunctivitis, eczema; $18.2 \%, 19.7 \%, 19.6 \%$ ) [51]. It is well known that asthma is more prevalent in urbanized areas as air pollution is one of the environmental factors that can exacerbate asthma. Differences in pollution levels might explain why the prevalence of current wheezing in Shika Town was higher than the Ogasawara Islands (less populated area) and lesser than Setagaya (one of the most populated area in Japan).

The prevalence of allergic rhinoconjunctivitis was only $5.3 \%$ in this study. The 
prevalence of allergic rhinoconjunctivitis in general population is reported to be more than $10 \%$ in recent studies of school children in developed countries [18]. Allergic rhinoconjunctivitis generally develops with gradual aeroallergen sensitization with seasonal allergens, mainly with cedar pollen or house dust mites in Japan [52]. Its prevalence peaked at 10 years old [51]. Therefore, the low prevalence of allergic rhinoconjunctivitis in this study is plausible.

Our findings are consistent with recent studies that found eczema was significantly more prevalent in children with ASD compared to children without ASD [13] [53] [54]. We could not find significant associations of autism spectrum features with asthma or allergic rhinoconjunctivitis. At present, explanations for the mechanisms driving the high prevalence of allergic diseases in children with ASD remain speculative. One possible explanation is that eczema symptoms affected SCQ total scores because the SCQ is a scale that assesses not only social interaction and communication but also behavioral symptoms. The discomfort and pain associated with allergic diseases would aggravate behavioral symptoms in children with ASD [55]. Jyonouchi pointed out that eczema tends to be underdiagnosed in ASD children because symptoms could be masked by associated behavioral problems [5]. Due to the cross-sectional design of our study, a cause-effect relationship between allergic symptoms and high SCQ score could not be determined. A future longitudinal study is therefore required to address this issue.

It should also be noted that our results suggested a significant association between obesity and asthmatic symptoms. The result is consistent with survey in Japan [56] and a meta-analysis of prospective epidemiological studies by Beuther and Sutherland showing a higher prevalence of asthma in overweight/obese people [57]. It is also well known that asthma is more likely to occur in boys compared to girls [58]. ASD has the same tendency as asthma in regard to weight abnormalities and sex: ASD is often associated with obesity and more prevalent in boys [39] [59] [60] [61] [62]. However, there are few studies investigating ASD and BMI in Japan. By investigating the differences in BMI and sex more deeply it might elucidate the cause(s) of ASD.

This study had methodological strengths. Study subjects were homogeneous with the same residential background. We realized a high valid response rate $(81.8 \%)$, surveyed $99 \%$ of the whole area population and minimized selection bias. The definitions of asthma, allergic rhinoconjunctivitis, and eczema were based on the ISAAC questionnaire which has been validated and used worldwide, however, it should be noted that wheezing in young children is not necessarily caused by allergies [63]. The definition of BMI categories were based on IOTF (now known as World Obesity) guidelines. Although a study in Belgium showed the inaccuracy of parentally reported weight and height for classifying preschool-aged children into BMI categories [64], in Japan, physical measurements are generally carried out monthly at preschools. Thus, we consider the BMI values in this study to be precise. 
Limitations of the present study other than mentioned above need to be noted. First, the main limitation of our study is the sample size of 417 children, which might not be large enough to identify significant differences of allergic symptoms between children with possible ASD and those without. The relatively small number of children with SCQ score $\geq 11$ suggests type II error, which restricts the power to detect relevant predictors. A careful interpretation of our findings is required in light of this. Future investigations with a larger sample could reveal significant relationships among allergic diseases and ASD. Second, we could not measure all variables that are likely to be a confounder in the association between allergic diseases and ASD (e.g. maternal status in pregnancy, or dietary habit). Third, we could not collect data from children who did not go to preschools. Children with severe behavioral problems might have been refused admission. Fourth, there is seasonal variation in reporting of allergic symptoms even though the questions asked about symptoms during the past year [65]. Finally, the extrapolation of conclusions from our study to other ethnicities/ cultures is limited by the fact that the participants were ethnically and culturally homogeneous.

\section{Conclusion}

Despite these limitations, this is the first study that used validated screening tools to assess the association between ASD and allergic symptoms in a general Japanese early childhood population. The study adds evidence that young children with possible ASD are more likely have eczema symptoms compared to others. These seminal results offer important clues to environmental influences on ASD and allergic diseases. Future studies using larger samples with a longitudinal design are needed to better characterize the causal association between ASD and allergic diseases.

\section{Acknowledgements}

The authors would like to thank the participants and the staff of preschools in Shika Town for their cooperation. The authors also thank Dr. Bryan J. Mathis of the Medical English Communication Center of the University of Tsukuba, Japan, for critical proofreading of this manuscript.

\section{Competing Interest}

The authors declare that they have no competing interests.

\section{References}

[1] American Psychiatric Association (2013) Diagnostic and Statistical Manual of Mental Disorders. 5th Edition, American Psychiatric Publishing, Arlington.

[2] Holgate, S.T. (2012) Innate and Adaptive Immune Responses in Asthma. Nature Medicine, 18, 673-683. https://doi.org/10.1038/nm.2731

[3] Wollenberg, A. and Klein, E. (2007) Current Aspects of Innate and Adaptive Im- 
munity in Atopic Dermatitis. Clinical Reviews in Allergy and Immunology, 33, 35-44. https://doi.org/10.1007/s12016-007-0032-9

[4] Newschaffer, C.J., Croen, L.A., Daniels, J., Giarelli, E., Grether, J.K., Levy, S.E., et al. (2007) The Epidemiology of Autism Spectrum Disorders. Annual Review of Public Health, 28, 235-258. https://doi.org/10.1146/annurev.publhealth.28.021406.144007

[5] Jyonouchi, H. (2010) Autism Spectrum Disorders and Allergy: Observation from a Pediatric Allergy/Immunology Clinic. Expert Review of Clinical Immunology, 6, 397-411. https://doi.org/10.1586/eci.10.18

[6] Angelidou, A., Alysandratos, K.-D., Asadi, S., Zhang, B., Francis, K., Vasiadi, M., et al. (2011) Brief Report: "Allergic Symptoms" in Children with Autism Spectrum Disorders. More than Meets the Eye? Journal of Autism and Developmental Disorders, 41, 1579-1585. https://doi.org/10.1007/s10803-010-1171-z

[7] Mostafa, G.A. and Al-Ayadhi, L.Y. (2013) The Possible Relationship between Allergic Manifestations and Elevated Serum Levels of Brain Specific Auto-Antibodies in Autistic Children. Journal of Neuroimmunology, 261, 77-81.

https://doi.org/10.1016/j.jneuroim.2013.04.003

[8] Theoharides, T.C. (2013) Is a Subtype of Autism an Allergy of the Brain? Clinical Therapeutics, 35, 584-591. https://doi.org/10.1016/j.clinthera.2013.04.009

[9] Kotey, S., Ertel, K. and Whitcomb, B. (2014) Co-Occurrence of Autism and Asthma in a Nationally-Representative Sample of Children in the United States. Journal of Autism and Developmental Disorders, 44, 3083-3088.

https://doi.org/10.1007/s10803-014-2174-y

[10] Akintunde, M.E., Rose, M., Krakowiak, P., Heuer, L., Ashwood, P., Hansen, R., et al. (2015) Increased Production of IL-17 in Children with Autism Spectrum Disorders and Co-Morbid Asthma. Journal of Neuroimmunology, 286, 33-41. https://doi.org/10.1016/j.jneuroim.2015.07.003

[11] Shibata, A., Hitomi, Y., Kambayashi, Y., Hibino, Y., Yamazaki, M., Mitoma, J., et al. (2013) Epidemiological Study on the Involvements of Environmental Factors and Allergy in Child Mental Health Using the Autism Screening Questionnaire. Research in Autism Spectrum Disorders, 7, 132-140. https://doi.org/10.1016/j.rasd.2012.06.003

[12] Berument, S.K., Rutter, M., Lord, C., Pickles, A. and Bailey, A. (1999) Autism Screening Questionnaire: Diagnostic Validity. The British Journal of Psychiatry, 175, 444-451. https://doi.org/10.1192/bjp.175.5.444

[13] Chen, M.H., Su, T.P., Chen, Y.S., Hsu, J.W., Huang, K.L., Chang, W.H., et al. (2014) Is Atopy in Early Childhood a Risk Factor for ADHD and ASD? A Longitudinal Study. Journal of Psychosomatic Research, 77, 316-321. https://doi.org/10.1016/j.jpsychores.2014.06.006

[14] Miyazaki, C., Koyama, M., Ota, E., Swa, T., Amiya, R.M., Mlunde, L.B., et al. (2015) Allergies in Children with Autism Spectrum Disorder: A Systematic Review and Meta-Analysis. Review Journal of Autism and Developmental Disorders, 2, 374-401. https://doi.org/10.1007/s40489-015-0059-4

[15] Elsabbagh, M., Divan, G., Koh, Y.J., Kim, Y.S., Kauchali, S., Marcin, C., et al. (2012) Global Prevalence of Autism and Other Pervasive Developmental Disorders. Autism Research, 5, 160-179. https://doi.org/10.1002/aur.239

[16] Blumberg, S.J., Bramlett, M.D., Kogan, M.D., Schieve, L.A., Jones, J.R. and Lu, M.C. (2013) Changes in Prevalence of Parent-Reported Autism Spectrum Disorder in School-Aged US Children: 2007 to 2011-2012. National Health Statistics Reports, $65,1-7$. 
[17] Kim, Y.S., Leventhal, B.L., Koh, Y.J., Fombonne, E., Laska, E., Lim, E.C., et al. (2011) Prevalence of Autism Spectrum Disorders in a Total Population Sample. American Journal of Psychiatry, 168, 904-912. https://doi.org/10.1176/appi.ajp.2011.10101532

[18] Asher, M.I., Montefort, S., Björkstén, B., Lai, C.K., Strachan, D.P., Weiland, S.K., et al. (2006) Worldwide Time Trends in the Prevalence of Symptoms of Asthma, Allergic Rhinoconjunctivitis and Eczema in Childhood: ISAAC Phases One and Three Repeat Multicountry Cross-Sectional Surveys. The Lancet, 368, 733-743. https://doi.org/10.1016/S0140-6736(06)69283-0

[19] Yura, A., Kouda, K., Iki, M. and Shimizu, T. (2011) Trends of Allergic Symptoms in School Children: Large-Scale Long-Term Consecutive Cross-Sectional Studies in Osaka Prefecture, Japan. Pediatric Allergy and Immunology, 22, 631-637. https://doi.org/10.1111/j.1399-3038.2011.01159.x

[20] Kamio, Y., Inada, N. and Koyama, T. (2013) A Nationwide Survey on Quality of Life and Associated Factors of Adults with High-Functioning Autism Spectrum Disorders. Autism, 17, 15-26. https://doi.org/10.1177/1362361312436848

[21] Brooks, W.T. and Benson, B.A. (2013) The Validity of the Social Communication Questionnaire in Adults with Intellectual Disability. Research in Autism Spectrum Disorders, 7, 247-255. https://doi.org/10.1016/j.rasd.2012.10.002

[22] Mandell, D.S., Wiggins, L.D., Carpenter, L.A., Daniels, J., DiGuiseppi, C., Durkin, M.S., et al. (2009) Racial/Ethnic Disparities in the Identification of Children with Autism Spectrum Disorders. American Journal of Public Health, 99, 493-498. https://doi.org/10.2105/AJPH.2007.131243

[23] Fujiwara, T. (2014) Socioeconomic Status and the Risk of Suspected Autism Spectrum Disorders among 18-Month-Old Toddlers in Japan: A Population-Based Study. Journal of Autism and Developmental Disorders, 44, 1323-1331. https://doi.org/10.1007/s10803-013-1988-3

[24] Rutter, M., Bailey, A. and Lord, C. (2003) The Social Communication Questionnaire: Manual. Western Psychological Services, Los Angeles.

[25] Williams, H., Robertson, C., Stewart, A., Ait-Khaled, N., Anabwani, G., Anderson, R., et al. (1999) Worldwide Variations in the Prevalence of Symptoms of Atopic Eczema in the International Study of Asthma and Allergies in Childhood. Journal of Allergy and Clinical Immunology, 103, 125-138. https://doi.org/10.1016/S0091-6749(99)70536-1

[26] Pearce, N., Aït-Khaled, N., Beasley, R., Mallol, J., Keil, U., Mitchell, E., et al. (2007) Worldwide Trends in the Prevalence of Asthma Symptoms: Phase III of the International Study of Asthma and Allergies in Childhood (ISAAC). Thorax, 62, 758-766. https://doi.org/10.1136/thx.2006.070169

[27] Kitaoka, M., Mitoma, J., Asakura, H., Anyenda, O.E., Nguyen, T.T.T., Hamagishi, T., et al. (2016) The Relationship between Hypertension and Health-Related Quality of Life: Adjusted by Chronic Pain, Chronic Diseases and Life Habits in the General Middle-Aged Population in Japan. Environmental Health and Preventive Medicine, 21, 193-214. https://doi.org/10.1007/s12199-016-0514-6

[28] Mitoma, J., Kitaoka, M., Asakura, H., Anyenda, E.O., Hori, D., Nguyen, T.T.T., et al. (2016) Prevalence of Chronic Pain, Especially Headache and Relationship with Health-Related Quality of Life in Middle-Aged Japanese Residents. Health, 8, 116124. https://doi.org/10.4236/health.2016.81014

[29] Kuroda, M. Inada, N. and Uchiyama T. (2013) SCQ Nihongoban. Kaneko Shobo, Tokyo. 
[30] Lord, C., Rutter, M. and Couteur, A. (1994) Autism Diagnostic Interview-Revised: A Revised Version of a Diagnostic Interview for Caregivers of Individuals with Possible Pervasive Developmental Disorders. Journal of Autism and Developmental Disorders, 24, 659-685. https://doi.org/10.1007/BF02172145

[31] Allen, C., Silove, N., Williams, K. and Hutchins, P. (2007) Validity of the Social Communication Questionnaire in Assessing Risk of Autism in Preschool Children with Developmental Problems. Journal of Autism and Developmental Disorders, 37, 1272-1278. https://doi.org/10.1007/s10803-006-0279-7

[32] Wiggins, L.D., Bakeman, R., Adamson, L.B. and Robins, D.L. (2007) The Utility of the Social Communication Questionnaire in Screening for Autism in Children Referred for Early Intervention. Focus on Autism and Other Developmental Disabilities, 22, 33-38. https://doi.org/10.1177/10883576070220010401

[33] Chandler, S., Charman, T., Baird, G., Simonoff, E., Loucas, T., Meldrum, D., et al. (2007) Validation of the Social Communication Questionnaire in a Population Cohort of Children with Autism Spectrum Disorders. Journal of the American Academy of Child and Adolescent Psychiatry, 46, 1324-1332. https://doi.org/10.1097/chi.0b013e31812f7d8d

[34] Ung, D., Johnco, C., McBride, N.M., Howie, F., Scalli, L. and Storch, E.A. (2016) Optimizing the Screening of Autism Spectrum Disorders in Outpatient Clinics: An Examination of the Social Communication Questionnaire-Lifetime. Research in Autism Spectrum Disorders, 27, 21-28. https://doi.org/10.1016/j.rasd.2016.03.011

[35] Barnard-Brak, L., Brewer, A., Chesnut, S., Richman, D. and Schaeffer, A.M. (2016) The Sensitivity and Specificity of the Social Communication Questionnaire for Autism Spectrum with Respect to Age. Autism Research, 9, 838-845. https://doi.org/10.1002/aur.1584

[36] Eaves, L.C., Wingert, H.D., Ho, H.H. and Mickelson, E.C. (2006) Screening for Autism Spectrum Disorders with the Social Communication Questionnaire. Journal of Developmental and Behavioral Pediatrics, 27, S95-S103. https://doi.org/10.1097/00004703-200604002-00007

[37] Nishima, S. and Odajima, H. (2002) Prevalence of Childhood Allergic Diseases in Japan Using International Study of Asthma and Allegies in Childhood (ISAAC) Phase I Protocal, Nihon Shoni arerugi gakkaishi. The Japanese Journal of Pediatric Allergy and Clinical Immunology, 16, 207-220. https://doi.org/10.3388/jspaci.16.207

[38] Miyake, Y., Sasaki, S., Tanaka, K., Ohfuji, S. and Hirota, Y. (2009) Maternal Fat Consumption during Pregnancy and Risk of Wheeze and Eczema in Japanese Infants Aged 16-24 Months: The Osaka Maternal and Child Health Study. Thorax, 64, 815-821. https://doi.org/10.1136/thx.2009.115931

[39] Tai, A., Volkmer, R. and Burton, A. (2009) Association between Asthma Symptoms and Obesity in Preschool (4-5 Year Old) Children. Journal of Asthma, 46, 362-365. https://doi.org/10.1080/02770900902759260

[40] Haby, M., Peat, J., Marks, G., Woolcock, A. and Leeder, S. (2001) Asthma in Preschool Children: Prevalence and Risk Factors. Thorax, 56, 589-595. https://doi.org/10.1136/thorax.56.8.589

[41] Peroni, D., Piacentini, G., Bodini, A., Rigotti, E., Pigozzi, R. and Boner, A. (2008) Prevalence and Risk Factors for Atopic Dermatitis in Preschool Children. British Journal of Dermatology, 158, 539-543. https://doi.org/10.1111/j.1365-2133.2007.08344.x

[42] Tai, A., Volkmer, R. and Burton, A. (2009) Prevalence of Asthma Symptoms and Atopic Disorders in Preschool Children and the Trend over a Decade. Journal of Asthma, 46, 343-346. https://doi.org/10.1080/02770900802660998 
[43] Cole, T. and Lobstein, T. (2012) Extended International (IOTF) Body Mass Index Cut-Offs for Thinness, Overweight and Obesity. Pediatric Obesity, 7, 284-294. https://doi.org/10.1111/j.2047-6310.2012.00064.x

[44] Cole, T.J., Bellizzi, M.C., Flegal, K.M. and Dietz, W.H. (2000) Establishing a Standard Definition for Child Overweight and Obesity Worldwide: International Survey. BMJ, 320, 1240-1245. https://doi.org/10.1136/bmj.320.7244.1240

[45] Cole, T.J., Flegal, K.M., Nicholls, D. and Jackson, A.A. (2007) Body Mass Index Cut Offs to Define Thinness in Children and Adolescents: International Survey. BMJ, 335, 194-201. https://doi.org/10.1136/bmj.39238.399444.55

[46] Ministry of Education, Culture, Sports, Science and Technology (2014) Annual Report of School Health Statistics Research.

http://www.mext.go.jp/component/b_menu/other/_icsFiles/afieldfile/2014/04/04/1 314157_3.pdf

[47] Sivertsen, B., Posserud, M.-B., Gillberg, C., Lundervold, A.J. and Hysing, M. (2012) Sleep Problems in Children with Autism Spectrum Problems: A Longitudinal Population-Based Study. Autism, 16, 139-150. https://doi.org/10.1177/1362361311404255

[48] Johnson, S., Hollis, C., Hennessy, E., Kochhar, P., Wolke, D. and Marlow, N. (2011) Screening for Autism in Preterm Children: Diagnostic Utility of the Social Communication Questionnaire. Archives of Disease in Childhood, 96, 73-77. https://doi.org/10.1136/adc.2010.194795

[49] McConachie, H. and Diggle, T. (2007) Parent Implemented Early Intervention for Young Children with Autism Spectrum Disorder: A Systematic Review. Journal of Evaluation in Clinical Practice, 13, 120-129. https://doi.org/10.1111/j.1365-2753.2006.00674.x

[50] Okada, Y., Kumagai, H., Morikawa, Y. and Akasawa, A. (2016) Epidemiology of Pediatric Allergic Diseases in the Ogasawara Islands. Allergology International, 65, 37-43. https://doi.org/10.1016/j.alit.2015.06.010

[51] Futamura, M., Ohya, Y., Akashi, M., Adachi, Y., Odajima, H., Akiyama, K., et al. (2011) Age-Related Prevalence of Allergic Diseases in Tokyo Schoolchildren. Allergology International, 60, 509-515. https://doi.org/10.2332/allergolint.10-OA-0293

[52] Ozasa, K., Hama, T., Dejima, K., Watanabe, Y., Hyo, S., Terada, T., et al. (2008) A 13-Year Study of Japanese Cedar Pollinosis in Japanese Schoolchildren. Allergology International, 57, 175-180. https://doi.org/10.2332/allergolint.O-07-513

[53] Chen, M.H., Su, T.P., Chen, Y.S., Hsu, J.W., Huang, K.L., Chang, W.H., et al. (2013) Comorbidity of Allergic and Autoimmune Diseases in Patients with Autism Spectrum Disorder: A Nationwide Population-Based Study. Research in Autism Spectrum Disorders, 7, 205-212. https://doi.org/10.1016/j.rasd.2012.08.008

[54] Yaghmaie, P., Koudelka, C.W. and Simpson, E.L. (2013) Mental Health Comorbidity in Patients with Atopic Dermatitis. Journal of Allergy and Clinical Immunology, 131, 428-433. https://doi.org/10.1016/j.jaci.2012.10.041

[55] Oza, V.S., Marco, E. and Frieden, I.J. (2015) Improving the Dermatologic Care of Individuals with Autism: A Review of Relevant Issues and a Perspective. Pediatric Dermatology, 32, 447-454. https://doi.org/10.1111/pde.12548

[56] Okabe, Y., Adachi, Y., Itazawa, T., Yoshida, K., Ohya, Y., Odajima, H., et al. (2012) Association between Obesity and Asthma in Japanese Preschool Children. Pediatric Allergy and Immunology, 23, 550-555. https://doi.org/10.1111/j.1399-3038.2011.01261.x 
[57] Beuther, D.A. and Sutherland, E.R. (2007) Overweight, Obesity and Incident Asthma: A Meta-Analysis of Prospective Epidemiologic Studies. American Journal of Respiratory and Critical Care Medicine, 175, 661-666. https://doi.org/10.1164/rccm.200611-1717OC

[58] Chen, Y., Dong, G., Lin, K. and Lee, Y. (2013) Gender Difference of Childhood Overweight and Obesity in Predicting the Risk of Incident Asthma: A Systematic Review and Meta-Analysis. Obesity Reviews, 14, 222-231. https://doi.org/10.1111/j.1467-789X.2012.01055.x

[59] Broder-Fingert, S., Brazauskas, K., Lindgren, K., Iannuzzi, D. and Van Cleave, J. (2014) Prevalence of Overweight and Obesity in a Large Clinical Sample of Children with Autism. Academic Pediatrics, 14, 408-414.

https://doi.org/10.1016/j.acap.2014.04.004

[60] Curtin, C., Jojic, M. and Bandini, L.G. (2014) Obesity in Children with Autism Spectrum Disorder. Harvard Review of Psychiatry, 22, 93-103.

https://doi.org/10.1097/HRP.0000000000000031

[61] Egan, A.M., Dreyer, M.L., Odar, C.C., Beckwith, M. and Garrison, C.B. (2013) Obesity in Young Children with Autism Spectrum Disorders: Prevalence and Associated Factors. Childhood Obesity, 9, 125-131. https://doi.org/10.1089/chi.2012.0028

[62] Zuckerman, K.E., Hill, A.P., Guion, K., Voltolina, L. and Fombonne, E. (2014) Overweight and Obesity: Prevalence and Correlates in a Large Clinical Sample of Children with Autism Spectrum Disorder. Jounal of Autism and Developmental Disorders, 44, 1708-1719. https://doi.org/10.1007/s10803-014-2050-9

[63] Brand, P.L., Baraldi, E., Bisgaard, H., Boner, A., Castro-Rodriguez, J., Custovic, A., et al. (2008) Definition, Assessment and Treatment of Wheezing Disorders in Preschool Children: An Evidence-Based Approach. European Respiratory Journal, 32, 1096-1110. https://doi.org/10.1183/09031936.00002108

[64] Huybrechts, I., De Bacquer, D., Van Trimpont, I., De Backer, G. and De Henauw, S. (2006) Validity of Parentally Reported Weight and Height for Preschool-Aged Children in Belgium and Its Impact on Classification into Body Mass Index Categories. Pediatrics, 118, 2109-2118. https://doi.org/10.1542/peds.2006-0961

[65] Yoshida, K., Adachi, Y., Sasaki, M., Furukawa, M., Itazawa, T., Hashimoto, K., et al. (2014) Time-Dependent Variation in the Responses to the Web-Based ISAAC Questionnaire. Annals of Allergy, Asthma and Immunology, 113, 539-543. https://doi.org/10.1016/j.anai.2014.07.027 
Submit or recommend next manuscript to SCIRP and we will provide best service for you:

Accepting pre-submission inquiries through Email, Facebook, LinkedIn, Twitter, etc. A wide selection of journals (inclusive of 9 subjects, more than 200 journals)

Providing 24-hour high-quality service

User-friendly online submission system

Fair and swift peer-review system

Efficient typesetting and proofreading procedure

Display of the result of downloads and visits, as well as the number of cited articles Maximum dissemination of your research work

Submit your manuscript at: http://papersubmission.scirp.org/

Or contact health@scirp.org 